\title{
Strategi Pemasaran Dalam Meningkatkan Volume Penjualan Pada Cafe Belly Buddy Ngagel Gubeng Surabaya
}

\author{
Almas Dhafin Umara' ${ }^{1}$ Budi Prabowo ${ }^{2}$ \\ ${ }^{1,2}$ Fakultas Ilmu Sosial dan Ilmu Politik, Universitas Pembangunan Nasional "Veteran" \\ umaradapin@gmail.com ${ }^{1 *}$;bprabowo621@gmail.com ${ }^{2}$
}

Received 02 Juli 2021| Revised 30 Juli 2021 | Accepted 27 September 2021

*Korespondensi Penulis

\begin{abstract}
Abstrak
Strategi Pemasaran merupakan aspek penting yang menunjang keberhasilan suatu usaha untuk dapat menembus pasar, dari beberapa strategi yang diterapkan, strategi pemasaran merupakan salah satu kunci untuk menaklukan persaingan dengan beberapa pesaing, Tujuan peneliti untuk mengetahui strategi pemasaran yang digunakan oleh Cafe Belly Buddy Surabaya dalam meningkatkan Volume penjualannya. Metode penelitian yang digunakan untuk penelitian ini adalah metode deskriptif yang merupakan bagian dari analisis kualitatif dengan menggunakan teknik pengambilan data secara observasi, dokumentasi dan wawancara mendalamyang berkaitan dengan strategi branding produk berdasarkan dengan menggunakan bauran pemasaran 7P yaitu Product, Place, Price, Promotion, Process, Physical Evidence, People yang digunakan oleh peneliti dalam menemukan kekuatan, kelemahan, peluang, dan ancaman dengan metode SWOT. Hasil dari penelitian ini Dengan melalui analisis IFAS (Internal Strategy Factor Analisis Sumarry) dan EFAS (Eksternal Strategy Factor Analisis Sumarry). Hasil skor dari faktor internal diperoleh kekuatan sebesar 2,22 dan kelemahan memiliki skor 1,20 , sedangkan dari faktor eksternal memiliki skor peluang 1,45 dan skor ancaman 1,49. Pilihan strategi adalahSO, sehingga pada diagram SWOT terletak di kuadran 2, yaitu walaupun terdapat berbagai ancaman, perusahaan ini masih memiliki kekuatan dari segi internal, strategi yang harus digunakan adalah dengan menggunakan kekuatan yang memanfaatkan peluang jangka panjang menggunakan strategi diverkasi (produk dan pasar)
\end{abstract}

Kata Kunci: Strategi Pemasaran; Bauran Pemasaran; Analisis SWOT

\begin{abstract}
Marketing strategy is an important aspect that supports the success of a business to be able to penetrate the market, from several strategies implemented, marketing strategy is one of the keys to conquering competition with several competitors, The aim of the researcher is to find out the marketing strategy used by Cafe Belly Buddy Surabaya in increasing the volume the sale. The research method used for this study is a descriptive method which is part of a qualitative analysis using data collection techniques by observation, documentation and in-depth interviews related to product branding strategies based on the 7P marketing mix namely Product, Place, Price, Promotion, Process, Physical Evidence, People used by researchers in finding strengths, weaknesses, opportunities, and threats with the SWOT method. The results of this study are through the analysis of IFAS (Internal Strategy Factor Analysis Sumarry) and EFAS (External Strategy Factor Analysis Sumarry). The results of the score from internal factors obtained strength of 2.22 and weakness had a score of 1.20, while the external factor had an opportunity score of 1.45 and a threat score of 1.49. The choice of strategy is SO, so the SWOT diagram is located in quadrant 2, that is, although there are various threats, this company still has internal strengths, the strategy that must be used is to use strengths that take advantage of long-term opportunities using a diversification strategy (product and market)
\end{abstract}


Keyword: Marketing Strategy; Marketing Mix; SWOT Analysis

\section{PENDAHULUAN}

Bisnis dalam dunia kuliner saat ini sangat berkembang pesat, salah satu faktor yang mendukung kemajuan dalam bidang kuliner adalah banyak saat ini berkembangnya cafe-cafe baru khususnya di sekitar kota Surabaya. Cafe berasal dari bahasa Perancis (café) yang artinya yaitu coffee, yang berarti kopi (Oldenburg, 1989: 126). Di Indonesia, kata café kemudian disederhanakan kembali menjadi kafe (Herlyana, 2012) pengertian harafiahnya mengacu pada (minuman) kopi, yang kemudian dikenal sebagai tempat menikmati kopi dengan berbagai jenis minuman non-alkohol lainnya seperti soft drink berikut sajian makanan ringan lainnya.

Tabel 1. Perkembangan Restaurant, Bar, Cafe yang sudah didaftarkan pada TDUP (Tanda Daftar Usaha Pariwisata) Surabaya.

\begin{tabular}{ccccc}
\hline Th 2014 & Th 2015 & Th 2016 & Th 2017 & Th 2018 \\
\hline 383 & 713 & 790 & 1083 & 1341 \\
\hline
\end{tabular}

(Sumber: Badan Pusat Statistik Provinsi Jawa Timur)

Bisnis cafe saat ini sangat di minati oleh orang-orang tentunya seiring dengan berkembangnya zaman dan perubahan gaya hidup di masyarakat.tentunya dalam berbisnis cafe ini memerlukan strategi pemasaran dan strategi bersaing untuk mengembangkan dan mempertahankan usaha cafe tersebut. Hal ini dapat dilihat dari jumlah cafe yang terus bertambah, baik dalam skala kecil maupun skala besar.

Menurut Lantip Diat Prasojo (2018:3) Strategi adalah gagasan dan tindakan untuk memahami dan mengamankan masa depan. Definisi ini menyoroti bahwa strategi memerlukan pemikiran tentang masa depan dalam upaya mewujudkan suatu konsepsi sehingga strategi memiliki banyak variasi.

Menurut Freddy Rangkuti (2017:6-7) Pada prinsipsnya strategi dapat dikelompokkan berdasarkan tiga tipe, yaitu: 1) Strategi Manajemen Merupakan strategi yang dapat dilakukan oleh manajemen dengan orientasi pengembangan strategi secara makro, seperti strategi pengembangan produk, strategi penetapan harga, strategi akuisisi, dan sebagainya; 2) Strategi Investasi Merupakan kegiatan yang berorientasi pada investasi, seperti strategi pertumbuhan agresif, strategi bertahan, strategi divestasi; 3) Strategi Bisnis Strategi ini sering disebut sebagai strategi bisnis fungsional karena strategi ini berorientasi pada fungsi-fungsi kegiatan manajemen, misalnya strategi pemasaran, strategi produksi, strategi keuangan, dan lain sebagainya.

Dikutip dari pernyataan Fandy Tjiptono (2016:3) menyampaikan bahwa pemasaran adalah aktivitas serangkaian institusi, dan proses menciptakan, mengkomunikasikan, menyampaikan, dan mempertukarkan tawaran yang bernilai bagi pelanggan, klien, mitra, dan masyarakat umum. Sedangkan menurut Menurut Philip Kotler dalam buku Thamrin Abdullah dan Francis Tantri (2017:14) mendefinisikan pemasaran sebagai suatu proses sosial dan manajerial dimana individu dan kelompok mendapatkan kebutuhan dan keinginan mereka dengan menciptakan, menawarkan, dan bertukar sesuatu yang bernilai satu sama lain.

Menurut Fandy Tjiptono (2015:17) strategi pemasaran dipandang sebagai upaya memaksimumkan peluang meraih bisnis yang ditargetkan melalui pengelolaan faktor-faktor yang dapat dikendalikan perusahaan, seperti desain produk, periklanan, pengendalian biaya dan pengetahuan pasar. Sedangkan menurut Abdul Manap (2016:73), unsur-unsur strategi pemasaran ada tiga, yaitu:

1. Segmentasi

Segmentasi pasar sebagai suatu proses membagi keseluruhan pasar (lingkungan) yang heterogen menjadi kelompok-kelompok yang lebih kecil dan homogen dengan kebutuhan yang relatif serupa yang diharapkan dapat dipenuhi oleh suatu perusahaan dengan baik. Segmentasi pasar 
membantu perusahaan untuk membuat suatu produk yang spesifik dan memenuhi kebutuhan sebagian pasar yang menjadi targetnya.

2. Targeting

Memilih satu atau lebih segmen pasar untuk dimasuki atau cara perusahaan untuk mengoptimalkan suatu pasar dan dalam penentuan target pasar perusahaan harus menggunakan konsep prioritas, variabilitas, dan fleksibilitas. Konsep variabilitas digunakan untuk menghadapi situasi persaingan yang sudah semakin meningkat, karena perusahaan tidak bisa memberikan pelayanan yang sama kepada semua orang yang sudah diprioritaskan. Semakin sama akan semakin tidak optimal, dan perusahaan dapat lebih optimal dalam melayani orang jika bisa memberikan lebih banyak variasi. Konsep fleksibilitas ada hubungannya dengan variasi tadi karena semakin fleksibel suatu 29 perusahaan dapat lebih banyak memberikan variasi tanpa banyak keluar ongkos tambah.

3. Positioning

Merupakan suatu usaha yang dilakukan oleh perusahaan dalam mendesain produk-produk mereka sehingga dapat menciptakan kesan dan image tersendiri dalam pikiran konsumennya sesuai dengan yang diharapkan.

Bauran pemasaran merupakan bagian dari konsep pemasaran yang mempunyai peranan yang cukup penting dalam mempengaruhi konsumen untuk membeli produk atau jasa yang ditawarkan. Kotler dan Armstrong (2014:76) mendefinisikan bauran pemasaran sebagai berikut, Marketing mix is the set of tactical marketing tools that the firms blends to produce the response it wants in the target market. Definisi tersebut menyatakan bahwa bauran pemasaran adalah seperangkat alat pemasaran taktis di perusahaan mamadukan dua hal yang menghasilkan respon yang diinginkan dalam pasar sasaran.

Menurut Kotler dan Keller (2016:47) empat variabel dalam bauran pemasaran memiliki komponen sebagai berikut: 1) Produk (Product) adalah suatu barang, jasa, atau gagasan yang dirancang dan ditawarkan perusahaan untuk kebutuhan konsumen; 2) Harga (price) adalah jumlah uang yang harus dibayar oleh pelanggan untuk memperoleh suatun produk; 3) Tempat (place) adalah penempatan suatu produk agar mudah dijangkau oleh segmen konsumen, sejenis aktivitas yang berkaitan dengan bagaimana menyampaikan produk dari produsen ke konsumen; dan 4) Promosi (promotion) adalah aktivitas mengkomunikasikan dan menyampaikan informasi mengenai produk kepada konsumen, dan membujuk target konsumen untuk membeli produk.

Pada perkembangannya, menurut Fandy Tjiptono (2014:43), teori bauran pemasaran juga disesuaikan dengan kondisi industri dimana industri jasa mengenal 3P tambahan sehingga menjadi 7P, yaitu: 1) Proses (Process) adalah dimana pelayanan menjadi perhatian, penciptaan dan pemberian elemen produk memerlukan desain dan pelaksanaan proses yang efektif; 2) Sarana Fisik (Physical Evidence) adalah desain dari penempilan pelayanan dari bangunan, landscaping, kendaraan, perabot interior, peralatan, seragam staff, signs, printed materials, dan sebagainya yang terlihat memberikan bukti nyata atas kualitas pelayanan perusahaan, fasilitas pelayanan, dan membimbing konsumen melalui proses pelayanan; dan 3) Orang (People) adalah individu yang berinteraksi langsung dengan konsumen yang membutuhkan kemampuan interpersonal yang baik dan sikap positif.

Ketujuh strategi di atas saling mempengaruhi sehingga semuanya penting sebagai satu kesatuan strategi dan berfungsi sebagai pedoman dalam menggunakan unsur-unsur atau variabel-variabel pemasaran yang dapat dikendalikan pimpinan perusahaan untuk mencapai tujuan perusahaan dalam bidang pemasaran

Penjualan Menurut Thamrin Abdullah \& Francis Tantri dalam Sudaryono (2016:55) menarik perbandingan antara konsep penjualan dan konsep pemasaran. Menjual memusatkan perhatian pada kebutuhan penjual, sedangkan pemasaran pada kebutuhan pembeli. Menjual terutama mementingkan kebutuhan penjual untuk menukar produknya menjadi uang tunai, sementara pemasaran mementingkan 
gagasan untuk memenuhi kebutuhan konsumen atas produk dan segala yang berkaitan dengan menciptakan, memberikan serta akhirnya menggunakan produk itu. Menurut Basu Swasta (2010:8) adalah: "Sistem keseluruhan dari kegiatan usaha yang ditujukan untuk merencanakan, menentukan harga, mempromosikan, dan mendistribusikan barang, jasa, ide kepada pasar sasaran agar dapat mencapai tujuan organisasi”.

\section{METODE}

Jenis penelitian yang dilakukan ini adalah penelitian deskriptif yaitu dengan cara menyajikan gambaran lengkap terkait suatu fenomena sosial dengan mengikut sertakan sejumlah variabel yang berkenaan dengan masalah yang sedang diteliti (Sugiyono,2015). Sedangkan metode yang digunakan dalam penelitian ini adalah metode kualitatif. Untuk memperjelas metode yang akan diterapkan berupa studi deskriptif dengan tujuan untuk menggambarkan realita sosial yang kompleks dengan menerapkan konsep-konsep teori yang telah ada. Realita sosial yang dipelajari dititikberatkan pada strategi pemasaran Cafe Belly Buddy Surabaya Ngagel

Dalam teknik analisis data penelitian ini digunakan metode deskriptif dan kemudian digunak ananalisis SWOT. Data deskriptif dihasilkan melalui wawancara mendalam (in-depht interview) kepada General Manager dan karyawan dengan strategi Pemasaran dengan menggunakan Bauran Pemasaran yang meliputi 7P hasil wawancara tersebut akan dianalisis menggunakan metode analisis SWOT yang meliputi Strenght (Kekuatan), Weakness (Kelemahan), Opportunities (Peluang), dan Threats (Ancaman).

\section{HASIL DAN PEMBAHASAN}

\section{Strategi Branding}

Hasil dari penelitian ini menunjukkan bahwa strategi pemasaran Cafe Belly Buddy dengan menggunakan bauran pemasaran 7P yaitu Product, Place, Price, Promotion, Process, Physical Evidence, People yaitu sebagai berikut:

a) Product

Menawarkan banyak varian produk mulai dari makanan dan minuman Indonesia, Asian, hingga produk makanan dan minuman Western

b) Price

Harga yang ditawarkan mulai dari Rp. 8000 sampai dengan Rp. 60.000

c) Place

Cafe Belly Buddy berlokasi di Jalan Raya Ngagel No. 209 bertempat di Rooftop Ruko

d) People

Karyawan di Belly Buddy berjumlah 13 orang yaitu 1 Head manager, 5 di Departemen Kitchen, 4 di Departemen Bar \& Service, 2 di Departemen Admin, dan 1 orang Security

e) Promotion

Sarana promosi Belly Buddy sudah mulai beranjak ke dunia digital dan Media Sosial seperti Instagram, TikTok, Facebook Business, dan Website sendiri.

f) Process

Proses yang dilakukan Cafe Belly Buddy sudah sesuai SOP perusahaan.

g) Physical Evidence

Pada usaha ini dinilai perlu untuk ditingkatkan sarana dan prasarananya guna dapat memberikan kenyamanan terhadap konsumen. 


\section{Analisis SWOT Pada Cafe Belly Buddy Strenght (Kekuatan)}

1. Berlokasi strategis

2. Lahan parkir luas

3. Pelayanan yang cepat dan ramah

4. Varian menu yang bermacam - macam (Western, Asian, Lokal)

5. Harga produk yang terjangkau

6. Hiburan Live Music setiap hari

7. Cafe yang luas dengan banyak meja dan kursi

8. Sudah terdapat banyak ulasan di google

\section{Weakness (Kelemahan)}

1. Bahan baku yang cepat habis

2. Kebersihan tempat yang relatif kurang

3. Kurangnya tenaga karyawan karena jumlah yang sedikit

\section{Opportunity (Peluang)}

1. Membuka cabang baru untuk memperluas pangsa pasar

2. Penambahan tenaga kerja untuk dapat meningkatkan efektifitas dan efisiensi pekerjaan

3. Penambahan varian menu untuk semakin menarik konsumen

4. Tersambung dengan layanan online atau digital seperti GoFood, GrabFood, Shopee pay, dll.

5. Mengundang Influencer dan Food Vlogger untuk me review produk Belly Buddy

6. Mengadakan event - event di hari tertentu, seperti Haloween, Hari kemerdekaan, Dsb.

\section{Threat (Ancaman)}

1.Kenaikan Harga bahan baku

2.Semakin banyaknya pesaing sejenis di bidang yang sama

3.Daya beli konsumen yang menurun berdasarkan kuantitas produk yang dibeli

4.Pandemi

Tabel 2. IFAS

\begin{tabular}{|c|c|c|c|c|c|}
\hline No & Faktor-Faktor Strategi Internal & Bobot & Rating & $\begin{array}{l}\text { Bobot } x \\
\text { Rating }\end{array}$ & Komentar \\
\hline A. & Kekuatan & & & & \\
\hline 1 & Lokasi strategis & 0,15 & 4 & 0,60 & Dipertahankan \\
\hline 2 & Lahan parkir yang luas & 0,07 & 4 & 0,28 & $\begin{array}{l}\text { Dipertahankan Dan } \\
\text { ditingkatkan }\end{array}$ \\
\hline 3 & Pelayanan yang cepat dan ramah & 0,08 & 3 & 0,24 & Dipertahankan \\
\hline 4 & $\begin{array}{l}\text { Harga yang cukup terjangkau untuk } \\
\text { kalangan cafe dan resto }\end{array}$ & 0,05 & 4 & 0,20 & $\begin{array}{l}\text { Dipertahankan dan } \\
\text { Ditingkatkan }\end{array}$ \\
\hline 5 & $\begin{array}{l}\text { Sudah banyak diulas di media sosial } \\
\text { dan google }\end{array}$ & 0,10 & 3 & 0,30 & Dipertahankan \\
\hline 6 & Hiburan Live musik setiap hari & 0,05 & 2 & 0,10 & Dipertahankan \\
\hline 7 & $\begin{array}{l}\text { Menerapkan Protokol kesehatan } \\
\text { yang tinggi }\end{array}$ & 0,07 & 3 & 0,21 & Dipertahankan \\
\hline \multirow[t]{2}{*}{8} & $\begin{array}{l}\text { Cafe yang luas dengan banyak } \\
\text { meja dan kursi untuk menampung } \\
\text { banyak pengunjung }\end{array}$ & 0,08 & 3 & 0,24 & $\begin{array}{l}\text { Dipertahankan dan } \\
\text { Ditingkatkan }\end{array}$ \\
\hline & Total & 0,65 & & 2,22 & \\
\hline B. & Kelemahan & & & & \\
\hline
\end{tabular}




\begin{tabular}{clcccc}
\hline No & Faktor-Faktor Strategi Internal & Bobot & Rating & $\begin{array}{c}\text { Bobot x } \\
\text { Rating }\end{array}$ & Komentar \\
\hline 1 & Bahan baku yang cepat habis & 0,15 & 4 & 0,60 & $\begin{array}{c}\text { Diperbaiki dan } \\
\text { ditingkatkan }\end{array}$ \\
\hline 2 & $\begin{array}{l}\text { Karyawan bagian service yang } \\
\text { sedikit jumlahnya menyebabkan } \\
\text { kurang tanggapnya pelayanan bila } \\
\text { cafe ramai }\end{array}$ & 0,12 & 3 & 0,36 & Ditingkatkan \\
\hline 3 & $\begin{array}{l}\text { Kebersihan tempat yang kurang } \\
\text { terjaga }\end{array}$ & 0,08 & 3 & 0,24 & Diperbaiki \\
\hline & Total & 0,35 & & 1,20 & \\
\hline Total Skor Internal & 1 & & 3,42 & \\
\hline
\end{tabular}

Dari hasil analisis tabel IFAS di atas, faktor kekuatan mempunyai nilai skor total (bobot $\mathrm{x}$ rating) $=2,22$ dan untuk faktor kelemahan mempunyai nilai skor total (bobot $\mathrm{x}$ rating) $=1,20$

Tabel 3. EFAS

\begin{tabular}{|c|c|c|c|c|c|}
\hline No & Faktor-Faktor Strategi Eksternal & Bobot & Rating & $\begin{array}{l}\text { Bobot x } \\
\text { Rating }\end{array}$ & Komentar \\
\hline A. & Peluang & & & & \\
\hline 1 & $\begin{array}{l}\text { Membangun cabang baru untuk } \\
\text { meningkatkan pangsa pasar }\end{array}$ & 0,11 & 4 & 0,44 & $\begin{array}{l}\text { Dipertahankan dan } \\
\text { ditingkatkan }\end{array}$ \\
\hline 2 & $\begin{array}{l}\text { Memaksimalkan perkembangan } \\
\text { teknologi dengan adanya GoFood } \\
\text { GrabFood }\end{array}$ & 0,11 & 3 & 0,33 & $\begin{array}{l}\text { Dipertahankan dan } \\
\text { ditingkatkan }\end{array}$ \\
\hline 3 & $\begin{array}{l}\text { Mengadakan event di hari - hari } \\
\text { besar atau tertentu }\end{array}$ & 0,06 & 2 & 0,12 & Dipertahankan \\
\hline 4 & $\begin{array}{l}\text { Menambah varian menu agar lebih } \\
\text { menarik pengunjung }\end{array}$ & 0,05 & 1 & 0,05 & Ditingkatkan \\
\hline 5 & $\begin{array}{l}\text { Bekerja sama dengan E-Payment } \\
\text { untuk mempermudah konsumen } \\
\text { membayar }\end{array}$ & 0,10 & 3 & 0,30 & Dipertahankan \\
\hline 6 & $\begin{array}{l}\text { Mengundang influencer dan food } \\
\text { vlogger }\end{array}$ & 0,05 & 1 & 0,5 & $\begin{array}{l}\text { Dipertahankan Dan } \\
\text { Ditingkatkan }\end{array}$ \\
\hline \multirow[t]{2}{*}{7} & $\begin{array}{l}\text { Menambah tenaga kerja khususnya } \\
\text { di divisi Bar \& Service }\end{array}$ & 0.08 & 2 & 0,16 & $\begin{array}{l}\text { Dipertahankan dan } \\
\text { ditingkatkan }\end{array}$ \\
\hline & Total & 0,56 & & 1,45 & \\
\hline B. & Ancaman & & & & \\
\hline 1 & $\begin{array}{l}\text { Pandemi Covid-19 dan peraturan } \\
\text { pemerintah terkait pembatasan ber } \\
\text { operasi }\end{array}$ & 0,10 & 4 & 0,40 & $\begin{array}{l}\text { Meningkatkan } \\
\text { Prokes }\end{array}$ \\
\hline 2 & $\begin{array}{l}\text { Semakin banyaknya pesaing sejenis } \\
\text { dibidang yang sama }\end{array}$ & 0,15 & 3 & 0,45 & $\begin{array}{l}\text { Perlunya } \\
\text { membangun } \\
\text { kepercayaan pada } \\
\text { konsumen }\end{array}$ \\
\hline 3 & $\begin{array}{l}\text { Daya beli konsumen yang menurun } \\
\text { akibat kuantitas pembelian }\end{array}$ & 0,07 & 4 & 0,28 & $\begin{array}{l}\text { Perlunya } \\
\text { meningkatkan } \\
\text { branding }\end{array}$ \\
\hline 4 & $\begin{array}{l}\text { Persaingan harga dengan Cafe baru } \\
\text { yang harganya lebih murah }\end{array}$ & 0,12 & 3 & 0,36 & $\begin{array}{l}\text { Membangun } \\
\text { kepercayaan } \\
\text { konsumen }\end{array}$ \\
\hline & Total & 0,44 & & 1,49 & \\
\hline
\end{tabular}




$\begin{array}{lll}\text { Total Skor Eksternal } & 1 & 2.94\end{array}$

Dari hasil analisis tabel EFAS di atas, faktor peluang mempunyai nilai skor total (bobot $\mathrm{x}$ rating) $=1,45$ dan faktor ancaman memiliki nilai skor total (bobot $\mathrm{x}$ rating) $=1,49$

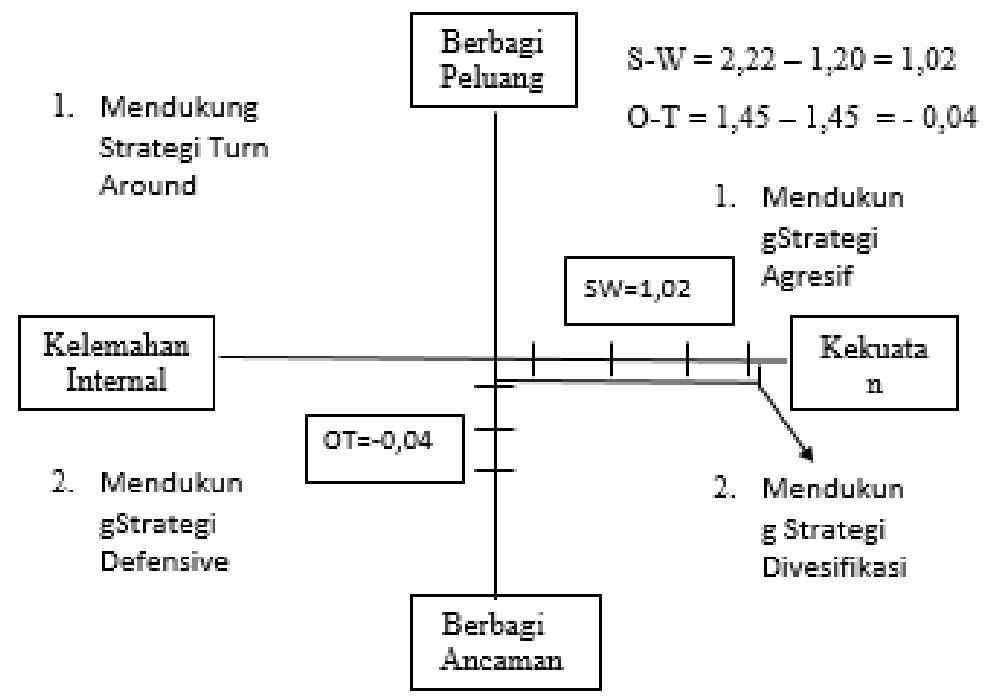

Gambar 2. Diagram Analisis SWOT

Dari hasil analisis diagram SWOT diatas menunjukan bahwa Cafe Belly Buddy berada di Kuadran 2 (dua). Walaupun terdapat berbagai ancaman, Cafe Belly Buddy ini masih memiliki kekuatan dari segi internal. Strategi yang harus diterapkan adalah dengan menggunakan kekuatan yang memanfaatkan peluang jangka panjang melalui strategi diversifikasi (produk atau pasar).

Strategi Diversifikasi yang dapat dilakukan oleh Cafe Belly Buddy adalah sebagai berikut:

1. Merekrut pegawai baru untuk memudahkan proses ,bisnis khususnya di bagian bar \& services, karena tenaga kerjanya masih kurang

2. Menambah beberapa menu varian baru namun tetap memperhatikan pasar, agar menarik perhatian konsumen sehingga konsumen selalu mencoba akan hal - hal baru yang man dalam memilih menu yang ada di Belly Buddy ditawarkan cafe Belly Buddy.

3. Mengundang beberapa influencer ternama dan food vlogger untuk dapat me - Review produk sehingga semakin banyak orang tahu akan produk dari Belly Buddy

4. Meningkatkan Brand Image dari Belly Buddy untuk dapat mengatasi pesaing pesaing yang ada di sekitar cafe, dengan menggiatkan promosi, konten, dan lain sebagainya

5. Mempertahankan harga yang terjangkau agar konsumen tetap memilih produk Belly Buddy

6. Mengoptimalkan proses distribusi bahan baku untuk meminimalisir kehabisan stok bahan baku

\section{SIMPULAN}

Berdasarkan hasil analisis yang dilakukan di Cafe Belly Buddy, Ngagel, Gubeng, Surabaya peneliti dapat menarik kesimpulan sebagai berikut:

1. Hasil dari penelitian ini menunjukkan bahwa strategi pemasaran Cafe Belly Buddy dengan menggunakan bauran pemasaran 7P yaitu Product, Place, Price, Promotion, Process, Physical Evidence, People yaitu sebagai berikut:

a. Product, menawarkan banyak varian produk mulai dari makanan dan minuman Indonesia, Asian, hingga produk makanan dan minuman Western

b. Price, harga yang ditawarkan mulai dari Rp. 8000 sampai dengan Rp. 60.000 
a. Place, Cafe Belly Buddy berlokasi di Jalan Raya Ngagel No. 209 bertempat di Rooftop Ruko

b. People, karyawan di Belly Buddy berjumlah 13 orang yaitu 1 Head manager, 5 di Departemen Kitchen, 4 di Departemen Bar \& Service, 2 di Departemen Admin, dan 1 orang Security

c. Promotion, sarana promosi Belly Buddy sudah mulai beranjak ke dunia digital dan Media Sosial seperti Instagram, TikTok, Facebook Business, dan Website sendiri.

d. Process, proses yang dilakukan Cafe Belly Buddy sudah sesuai SOP perusahaan.

e. Physical Evidence, pada usaha ini dinilai perlu untuk ditingkatkan sarana dan prasarananya guna dapat memberikan kenyamanan terhadap konsumen.

2. Dengan melalui analisis IFAS (Internal Strategyy Factor Analysis Summary) dan EFAS (External Strategy Factor Analysis Summary) dapat diketahui bahwa Cafe Belly Buddy memiliki skor internal yaitu kekuatan sebesar 2,22 dan kelemahan memiliki skor 1,20 sedangkan dari Faktor eksternal memiliki skor peluang 1,45 dan skor ancaman 1,49.

3. Dari hasil analisis diagram SWOT menunjukan bahwa Cafe Belly Buddy berada di Kuadran 2 (dua). Walaupun terdapat berbagai ancaman, Cafe Belly Buddy ini masih memiliki kekuatan dari segi internal. Strategi yang harus diterapkan adalah dengan menggunakan kekuatan yang memanfaatkan peluang jangka panjang melalui strategi diversifikasi (produk atau pasar).

\section{Ucapan Terima Kasih}

Pada kesempatan ini peneliti menyampaikan terima kasih kepada seluruh pihak yang telah membantu peneliti dalam menyelesaikan penelitian ini diantaranya Ibu Manager yaitu Diah Rian yang telah memperkenankan Belly Buddy sebagai objek penelitian ini, serta seluruh karyawan yang telah meluangkan waktunya untuk kegiatan wawancara dalam penelitian ini, peneliti ucapkan juga kepada teman-teman saya yang telah membantu, dan mensuport dalam menyelesaikan penelitian ini, semoga penelitian ini dapat berguna bagi orang yang membacanya dan bermanfaat untuk referensi penelitian selanjutnya.

\section{DAFTAR PUSTAKA}

Armstrong, Kotler.2015. Marketing and Introducing Prentice Hall 12th Edition.

England:Pearson Education, INC

Diatprasojo, Lantip.2018.Manajemen Strategi.Yogyakarta:UNY Press

Freddy Rangkuti, 2009, Strategi Promosi Yang Kreatif, edisi pertama, cetakan pertama, Penerbit

: Gramedia Pustaka Utama, Jakarta

Herlyana, Elly. 2012. Fenomena Coffee Shop Sebagai Gejala Gaya Hidup Baru Kaum Muda. Program Studi Sejarah dan Kebudayaan Islam. Fakultas Adab dan Ilmu Budaya. Universitas Islam Negeri Sunan Kalijaga. Yogyakarta

Kotler, Philip dan Kevin L. Keller. 2016. Marketing Management, 15th Edition. England: Pearson Education, INC

Malau, Harman.2018.Manajemen Pemasaran.Bandung: Alfabeta, cv

Ninemeier, J. D. dan Hayes, D. K. 2011. Restaurant Operations Management. Pearson Prentice Hall, New Jersey.

Oldenburg, Ray. (1989). The Great Good Place: Cafes, Coffee Shops, Bookstores, Bars, Hair Salons, and other Hangouts at The Heart of a Community. London: Da Capo Press

Pasaribu, Rowland Bismark Fernando. 2015. Manajemen Strategi, Universitas Gunadarma Jakarta

Rangkuti, Freddy. 2017.Analisis SWOT, Cetakan keduapuluh.Jakarta: PT Gramedia Pustaka Utama

Rivai, A., \& Prawironegoro, D.2015. Manajemen Strategis.Jakarta:Mitra Wacana Media 
Satori, Djam'an dan Aan Komariah. 2017. Metodologi Penelitian Kualitatif. Bandung: Alfabeta, $\mathrm{cr}$

Setiyaningrum, Ari dkk. 2015. Prinsip-prinsip Pemasaran. Yogyakarta: CV Andi Offset Suci, Rahayu Puji. 2015. Esensi Manajemen Strategi. Sidoarjo: Zifatama Publisher Sudaryono.2016. Manajemen Pemasaran Teori dan Implementasi.Yogyakarta: CV Andi Offset Sugiyono. 2017. Metode Penelitian Kuantitatif, Kualitatif, dan R\&D, cetakan ke-25. Bandung: Alfabeta,c

Swasta, Basu, 2010. Azas-asas Marketing Edisi 3. Yogyakarta: Akademi Keuangan.

Tjiptono,Fandy. 2015.Strategi Pemasaran.Yogyakarta: CV.Andi Offse 